\title{
AC 2010-1231: GRADUATE STUDENT QUALIFYING EXAM APPROACH: COURSE TO GUIDE STUDENTS THROUGH WRITING A RESEARCH PROPOSAL
}

\section{Adrienne Minerick, Mississippi State University}

Adrienne Minerick is an Associate Professor of Chemical Engineering at Michigan Technological University having recently moved from Mississippi State University, where she was a tenured Associate Professor. She received her Ph.D. and M.S. from the University of Notre Dame and B.S. from Michigan Tech. At MTU, Adrienne has taught graduate kinetics. At MSU, she taught graduate Chemical Engineering Math, Process Controls, Introduction to Chemical Engineering Freshman Seminar, Heat Transfer, and Analytical Microdevice Technology courses. In addition, she is an NSF CAREER Awardee, has served as co-PI on an NSF REU site, PI on grants from NSF and DOE, and was the faculty advisor for MSU's chapter of the National Organization for the Professional Advancement of Black Chemists and Chemical Engineers (NOBCChE). Her research is in medical microdevice diagnostics \& dielectrophoresis.

\section{Rafael Hernandez, Mississippi State University}

Rafael Hernandez is an Associate Professor of Chemical Engineering. He has a BS (1993) and MS (1995) in chemical engineering from the University of Puerto Rico, Mayaguez, and a PhD (2002) in chemical engineering from Mississippi State University (MSU), Mississippi State, MS. He worked for the US Army Corp of Engineers Engineering Research and Development Center on the development, design, and implementation of groundwater treatment technologies. His research interests are the development of technologies for the remediation of contaminated media and the development of non-traditional feedstocks for producing biofuels. Dr. Hernandez has over 80 technical presentations at state and national conferences and over 15 peer reviewed publications. He is the principal investigator on projects funded by the Department of Energy, the Environmental Protection Agency, and private industries. 


\title{
Graduate Student Qualifying Exam Approach: Course to Guide Students Through Writing a Research Proposal
}

\begin{abstract}
This paper describes a new course at Mississippi State University that provides structured guidance on writing an NSF research proposal. Course development was guided by personal communications with David F. Ollis and his 1995 article $^{1}$ in Chemical Engineering Education on "The Research Proposition." The endearing premise of this proposal-based qualifying exam is that writing a research proposal is a learning tool that teaches tangible research skills which students do not gain in their traditional graduate coursework. This course was focused for first to second year Ph.D. graduate students in chemical engineering and doubled as the Ph.D. qualification exam. This semester-long course included incremental milestones for the student and regular feedback from the instructors. The final product of the course was a 15 page NSF style research proposal and a 20-minute oral presentation on the proposal before a faculty committee. As students progress through the course, they are taught and then asked to demonstrate the tools, skills and knowledge to:

- Assimilate information from a comprehensive (yet succinct and thorough) literature review on a given research topic,

- Identify and articulate knowledge missing from the research field,

- Develop a well-defined hypothesis that probes an important and relevant research problem,

- Describe a detailed method of approach (experimental or otherwise) to obtain the missing knowledge,

- Outline data analysis / interpretation as well as the nature and impact of expected results,

- Contextualize the importance of their proposed idea within the larger research field,

- Craft supporting documents such as the Budget, Biosketch, and Facilities and Resources.
\end{abstract}

In addition to evaluations of each student by a committee of faculty, the students and faculty were asked to complete formative assessment surveys. All surveys, procedures, and tools were approved by Mississippi State University's Institutional Review Board for the protection of human subjects. The 6 students enrolled in the summer 2009 course were asked to complete precourse and post-course surveys on their self-measured skills and attitudes. Individual responses were recorded and paired between pre and post surveys; group trends were then compiled. Responses for questions were all cast on a 5 point Likert scale with 5 being the highest rating, 3 as neutral and 1 as the lowest rating. The faculty were asked to assess the student performances and to compare them to prior years where students were required to write a research proposal, but were not given guidance on developing the proposal. This paper will describe the course structure and then discuss the assessment tools and results for the summer 2009 cohort compared to $\sim 3$ years of qualifying exams without the course instruction.

\section{Introduction}

Expectations and skills needed to succeed in graduate school are different than in undergraduate curriculums. However, many graduate programs still use proficiency on course-derived 
knowledge as the criteria for qualifying for graduate school. In 2004 the faculty of the Dave C. Swalm School of Chemical Engineering decided to change the qualifying examination, required for Ph.D. candidacy, from an exam on chemical engineering graduate and undergraduate courses to preparation of a research proposal followed by its defense before a faculty committee. The idea was to provide graduate student with an opportunity to develop the skills of generating and defending an original research idea. Skills they would later need to develop a research program in academia or implement/modify processes in industry.

First implementation of the new qualifying exam was criticized as having shortcomings by the faculty and students. The first step of the process was topic approval by the student's graduate committee. Once the student provided a short presentation on the selected idea, the committee decided on originality since the topic had to be completely different from the student's dissertation work. Following topic approval, the student was given two months to write an NSF style proposal. No guidance from the committee or other faculty members was allowed during this period. Finally, the student submitted the written proposal, which was defended before the graduate committee two weeks later.

The fact that no guidance was provided resulted in several poor quality proposals. Many of the students had to repeat the exam before passing. Since the premise of the new qualifying exam was that writing a research proposal is a learning tool that teaches tangible research skills which students do not gain in their traditional graduate coursework, in 2008 the faculty decided to implement the research proposition course as part of the qualifying examination requirements. The first iteration of the course was taught during the summer 2009.

Dr. Dave Ollis from North Carolina (NC) State University met with the course instructors midSpring 2009 and shared course materials, recommended texts ${ }^{2-5}$ and his experiences from a similar course he teaches at NC State. The chemical engineering faculty at NC State decided to change to the research proposition course in the early 1990s and Dr. Ollis has taught the course since its inception into the graduate program. Additional U.S. graduate programs include required courses in the curriculum on writing research proposals (University of Oklahoma ${ }^{6}$ ) and research methods (Michigan Technological University and Arizona State University ${ }^{8}$ ). Structured training in research methods is also endorsed in international communities such as in Ersta Sköndal University College in Stockholm, Sweden ${ }^{9}$ and National University of Singapore ${ }^{10}$. Some programs provide training on the research proposition or research methods via workshops or on the job training ${ }^{11-13}$. Most programs leave this aspect of graduate school experience entirely to the one-on-one mentoring between advisors and their graduate students ${ }^{14}$. A variety of books are also available for students on the research methodology ${ }^{15}$, navigating advanced degree training and careers ${ }^{16,17}$, and advice on writing and publishing papers in engineering ${ }^{18-20}$. At Mississippi State, the faculty thought it would be more time efficient and yield better-trained students to provide centralized instruction on formulating a research proposition, developing a research methodology, and communicating the entire project via a written proposal and oral defense.

The MSU instructors, students, and faculty members involved in the proposal evaluation committees considered the first iteration of the course a success. The students received incremental training on proposal preparation during the Summer 2009. The final product was an 
NSF style proposal, which the students defended before committees composed of faculty from multiple colleges. The faculty members indicated a vast improvement in the quality of the proposals and presentations compared to the no guidance examination. The student's feedback was positive. They developed skills valuable, not only for preparation of research proposals, but peer-reviewed publication, dissertation, and final defenses. Below is a description of the topics included in the course, and the evaluations provided by the students and faculty.

\section{Course Structure \& Content}

The objective of this course was to provide structured guidance on writing an NSF research proposal. A number of resources were consulted and utilized as reference materials for the students and instructors ${ }^{2-5}$. This course was focused for first to second year Ph.D. graduate students. It was assumed that these students had experience and were proficient with:

- Reading, critiquing and assimilating information from archival technical journal articles.

- Foundational knowledge in their discipline.

- Foundational knowledge in given research field.

- Design of an experimental plan.

The endearing premise of this proposal-based qualifying exam was that writing a research proposal is a learning tool that teaches tangible research skills which students do not gain in their traditional graduate coursework. This semester-long course included incremental milestones for the student and regular feedback from the instructors. The final product of the course was a 15 page NSF style research proposal and a 20-minute oral presentation on the proposal before a faculty committee selected by the course instructors. All performance evaluations were incorporated into a final grade for the course. Of the 6 students enrolled in the course in Summer 2009 , three were chemical engineering students and needed to earn a satisfactory grade in the course to continue in the Ph.D. program.

The subjects covered in the class are listed below (NOTE: last names are placeholders only). The items in bold under the main number headings outline the activities or assignments that the students were to complete. A schedule of due dates is provided in Figure 1.

1) Introduction and Overview (Minerick / Hernandez)

a. Identification of a preliminary topic, demonstrate originality from advisor's proposal (include as reference in student's proposal)

2) Electronic searching (post 1995) and library (pre-1995) resources (D. Lee)

3) Keeping up with the literature, journal clubs (Minerick)

a. Mock review of papers

4) Anatomy of a proposal (Hernandez)

5) Research: Proposition structure and substance (Hernandez)

a. Students serve on a review panel (NSF proposals)

6) Writing styles: informative, concise, and complete (Minerick)

7) Reverse engineering of a proposal (from articles in 3a) (Minerick)

a. DUE: 3 page proposal

8) Advisor expectations of graduate student assistants - communication (Hernandez)

9) Finalize research topic for your proposition (Hernandez)
a. DUE: Student's 1-page proposition with clear proposal objectives 
10) Proposal Budgets (S. Denson)

a. DUE: First draft of Budget, Budget Justification

11) Discussions with Instructors: Feedback on research topic with input from advisors

12) Technical meetings and presentations (Hernandez)

a. DUE: Biographical sketch

13) Proposition outline (Minerick)

a. DUE: 2 page outline

14) Style in writing proposals (Minerick)

a. DUE: Motivation, Hypothesis (mark originality), and Literature (presuppositions) ( $>4$ pages)

15) Intellectual Property (C. Rivenburgh)

16) Experiment / simulation: Methods planning (Minerick prepare notes, Hernandez give lecture)

a. DUE: Methods section matching revised proposal objectives ( $>4$ pages), Facilities

17) Ph.D. / M.S. jobs in industry / National Labs - writing proposals in this atmosphere (Hernandez)

18) Mentoring \& educational efforts to compliment research (Minerick)

a. DUE: Mentoring \& education sections of proposal (1.5 pages)

19) Intellectual Merit \& Broader Impacts (Hernandez)

a. DUE: Draft of Project Summary (1 page)

20) DUE: Penultimate draft of proposal

a. Discussions with Instructors: Feedback on draft proposal

21) Oral Presentations tips

a. Style and substance (Hernandez)

b. Speaker, slides, audience (Minerick)

c. DUE: Outline of presentation

22) DUE: Final Proposal distributed to committees (24 July)

a. Review of document using rubric provided

23) Prepare slides for presentation

a. DUE: Presentation slides

b. Practice with Instructors: Feedback on presentation slides (30 \& 31 July)

24) Topic oral presentations in front of committees

a. Review of presentation using rubric provided 


\section{ChE 8990: The Research Proposition Summer 2009}

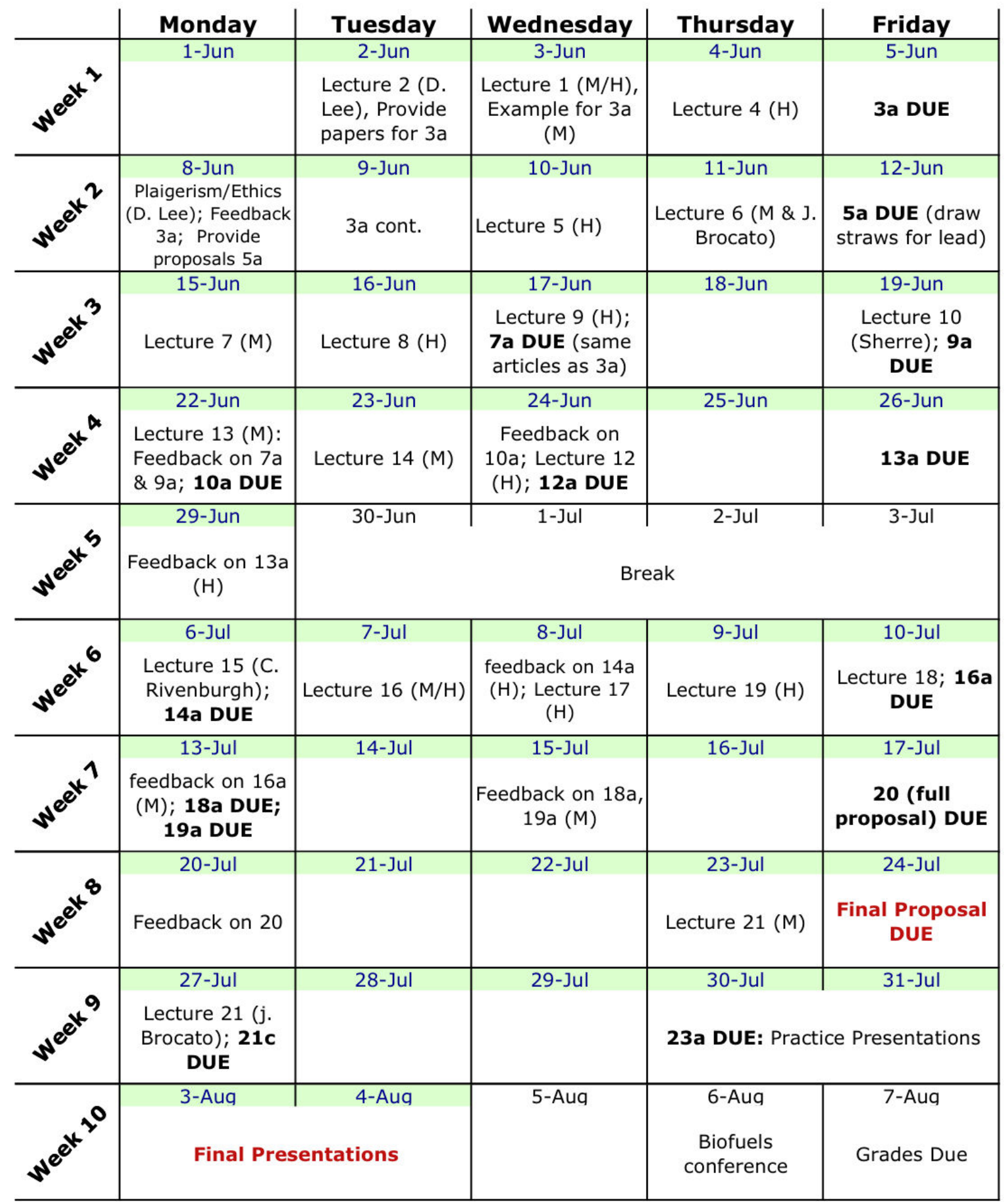

Figure 1: Schedule of assignments, lectures, and activities in the research proposition course. 
This was probably one of the most writing intensive courses these students had been enrolled in since beginning graduate school. For this reason, originality of the writing was highly stressed. The policy was clearly communicated in the syllabus and a special session was conducted by library personnel on plagiarism. Students were told that all written prose and intellectual products generated in the class must be original. This means that the student needs to generate these independently. Ideas may not be duplicated from any source other that the student's own knowledge / research ideas. Written prose (paragraphs, sentences, or phrases) may not be copied electronically (or otherwise) and pasted into any documents generated for the class. Concept progression may not be mimicked or duplicated for this class. Figures can only be reproduced if clearly cited with the phrase, "Copyright [PUBLISHER], [YEAR], [reference \#]. Permission not attained for class purposes." We used www.turnitin.com to help assess originality $^{21}$. All assignments were submitted electronically to this service and a hardcopy was turned into the instructors. Every student's advisor was invited to read the final proposal and provide feedback on originality of the research ideas included in the proposal. The educational efforts in this area were deemed successful because a) all final proposals achieved greater than $95 \%$ originality and b) all advisors certified that the work produced was original.

\section{Assessment Results}

Students were asked to complete a survey (provided in the Appendix) at the beginning of the course and at the end of the course. They were asked their birth date and phone number such that these two surveys could be matched together to compare changes person by person yet still remain as anonymous as possible. Faculty were also asked to complete a survey immediately after their assessments of the final student products, which is also available in the Appendix and is discussed in the next subsection.

\section{Student Assessment Results}

The pre and post course surveys were broken into five sections as follows: A - attitudes and time, $\mathrm{B}$ - reading, critiquing and assimilating information from archival technical journal articles, $\mathrm{C}-$ knowledge and design of experimental plan, D - assimilate information from a comprehensive (yet succinct and thorough) literature review on a given research topic, and E- other skill sets. In each section, the responses were coded into a similar 5-point scale, which is shown in Table 1.

Table 1: Key matching the numerical score associated with survey responses.

\begin{tabular}{|l|l|l|l|l|}
\hline Key: & Section A & Section A & Section B, D, E & Section C, E \\
\hline $\mathbf{5 =}$ & Very Scared & essential skills & Strongly Agree & Excellent \\
\hline $\mathbf{4 =}$ & Scared & some skills & Agree & Very Good \\
\hline $\mathbf{3 =}$ & Neutral & Neutral & Neutral & Good \\
\hline $\mathbf{2}=$ & Easy & no skills & Disagree & Fair \\
\hline $\mathbf{1}=$ & Piece of cake & no benefit at all & Strongly Disagree & Poor \\
\hline
\end{tabular}

In section A - Attitudes and time, students were asked what their feelings were toward this class which overall at the beginning were neutral with a slight bias toward scared (3.2 in Figure 2). By the end of the class, the feelings were simply neutral. When asked at the beginning of the class about their attitude regarding what they would learn, students overall thought the course would provide them with useful skills (4.3 in Figure 2). By the end of the class, this attitude had shifted 
heavily to the strongest response (4.8 in Figure 2) which was, "this course taught me essential skills that will or has already made me better / more productive as a graduate student." Most students expected to spend 11 to 20 hours per week on the course, but a couple expected to spend 21 to 30 hours per week. At the end of the course, the amount of time students reported dedicating to the class varied from the 11-20 hours per week ( 3 students) to greater than 30 hours per week (2 students).

In section B - Proficiency in reading, critiquing and assimilating information from archival technical journal articles, students were asked to rate their self-determined experience conduction literature searches (question 4), confidence in obtaining a complete profile of published work on a topic (question 5) and experience reading the articles to understand and extract information (question 6). At the beginning of the class, students rated themselves above neutral in these areas at 3.7, 3.8, and 3.5 respectively which changed to $4.3,4.2$, and 3.6 respectively by the end of the course. Question 4 and 5 saw increases above the 'Agree' response, but the rating for experience reading the articles didn't change. This could be due to the students realizing upon questioning by their faculty committee that they understood less than they originally thought. However, this has been identified as a potential area for improvement for the 2010 course.

In section $\mathrm{C}$ - Knowledge and design of experimental plan, students rated their foundational knowledge in the discipline (question 7) and in their research field (question 8) followed by selfdetermining their ability to design a comprehensive experimental plan (question 9). At the beginning of the class, students rated themselves around the 'Good' range for all questions (3.2, 3.0 , and 2.8, respectively) and this changed only slightly above 'Good' by the end of the class $(3.3,3.2$, and 3.6). Since the students had delved so deeply into a specific research topic, we had expected that knowledge in their discipline would have a minor increase and knowledge in their research field would substantially increase. The knowledge in their research field might not have increased as much because the students gained a greater appreciation for how much information existing on their given field. Of course, this will be explored further in subsequent years. There was an increase observed in their ability to design an experimental plan. This increase was not as great as the instructor's desired and so additional attention will be dedicated to this subject in 2010.

Students also made comments in response to the questions in sections A, B, and C. The precourse comments were:

* I have experience in doing research in my MS thesis, but my friends and advisor and coadvisors help me a lot. It was a tough work for me and it will take a lot of time and effort to complete it, but I am satisfied with the result.

* Language barrier (I'm not comfortable in speaking English)

* My background prior to Mississippi State was Master of Arts. There has been a learning curve over the last year. So, I am still figuring some things out. I have recently finished my literature review for my project. With no basic knowledge of the field, I found myself struggling to read the literature and understand articles.

The comments post-course were:

* The proposal process has helped me be able to think through and communicate plans better and to also look into other details of my proposal that I might have overlooked before. 
Section D dealt with assimilating information from a comprehensive (yet succinct and thorough) literature review on a given research topic. Students were asked 5 questions that included adapting techniques from articles into research (question 11), critiquing techniques and conclusions asserted in the literature (question 12), compiling survey of literature, organizing it, and presenting it to show progression of knowledge and missing information (question 13), experience analyzing raw data to determine trends and dependencies (question 14), and experience writing research articles that combine skills in questions 11 through 14 (question 15). Recalling that the students enrolled in this course were first and second year students in the Ph.D. program, their self-rated proficiencies were much higher than expected. At the beginning of the course, students felt they could recognize and adapt techniques from articles as long as they could discuss those with others with a slight bias towards complete independence in doing this (rating of 4.2). By the end of the class, this overall rating had fallen to 3.8. This change is (hopefully) to a greater understanding of the breadth and depth of a given field. Students rated their experience critiquing articles between neutral where they needed guidance to agree where they demonstrated some independence (3.5 at course start) and this increased to a greater overall independence (4.1) by the end of the course. The students self-rated skills compiling the literature, organizing it, and recognizing missing information did not change substantially from course beginning to course end (4.0 to 4.2). While the course did not involve practice analyzing raw data, it did involve describing how the data analysis would be conducted. Pre and post course ratings in this area increased from 3.7 to 4.2. Experience writing research articles was rated 3.7 in the beginning and 4.0 in the end although only two students in the class had actually published a peer-reviewed research article. This rating is indicative of a mismatch between the skill level students feel they have and the skill level faculty feel the students have (will be discussed at the end of this section).

The last section in the survey was E - other skill sets. Question 16 asked students to rate their ability to articulate knowledge missing from their research field which was fair to good at the start of the course (2.7 in Figure 2) and Good to Very Good (3.5 in Figure 2) by the end of the course. Question 17 asked ability to develop a well-defined hypothesis to probe an important and relevant research problem changed from 3.3 to 3.6. This was an area where the instructors really had to work with students to have them revise un-testable statements that lacked focus. The instructors felt that at the beginning of the class, students answered this question without truly understanding what a hypothesis was. Next, question 18 asked ability to describe a detailed method of approach to obtain missing information. Students answered showed great variability, but averaged to 'good' (3.0) at the beginning of the class. By course completion, this was 3.8 which was almost into the very good range. Question 19 probed abilities to describe in detail how data analysis and interpretation was conducted as well as speculate on the impact of expected results. Pre-course responses were 3.5 while post course responses were 3.3. This was another area where the student's initial drafts were severely lacking in discussion and the instructors had to provide substantiative guidance and feedback to improve the proposals to the level that the faculty rated them in the next section. Question 20 asked students their ability to contextualize the importance of their topic within the larger research field, which they rated as 'good = sufficient with guidance' at the beginning and halfway between good and 'very good = could do as good as my professors, but it would take me longer' at the end of the class (3.0 and 3.5, respectively in Figure 2). At the beginning of the course, students were neutral to disagree 
(2.7) regarding having experience crafting Budget, Biosketch, and Facilities documents, which improved to 3.8 by the end of the course. All of these results are summarized in Figure 2.

Average Self-Evaluated Attitudes and Skills at the Beginning and End of the Course

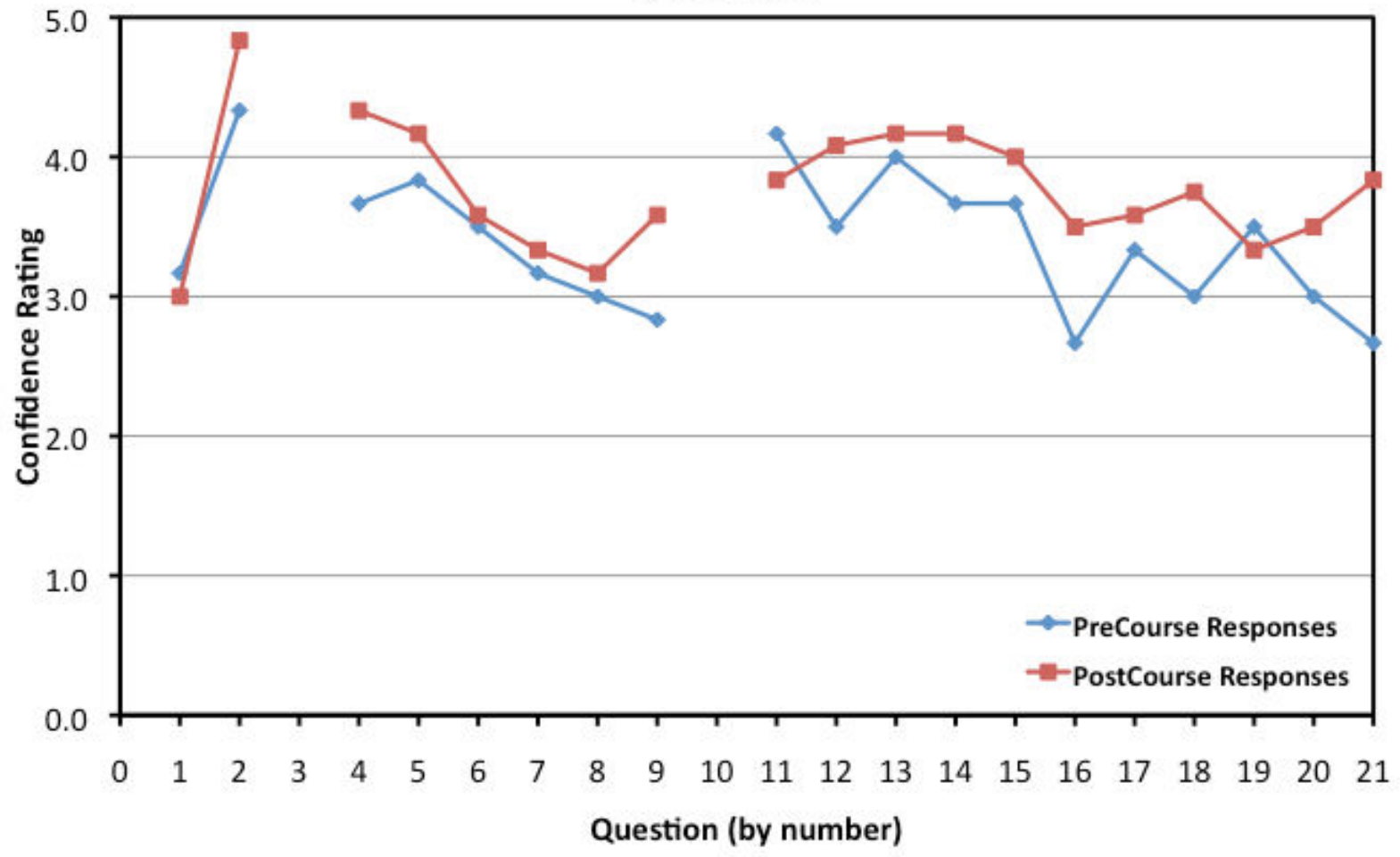

Figure 2: Average results of the student survey showing responses by question number at the beginning of the course (blue diamonds) and at the end of the course (red squares).

Students were given the opportunity to openly comment on any of the survey questions that addressed skilled taught in the course which were questions 11 through 21 . At the beginning of the course, responses were:

* I totally feel that I will obtain a lot of experiences in this course and feel my progress. But I think that I need more time and experience to be perfect but the approach and knowledge that I learn in this course can help me to go in right way and it will be easier for me to do my future research because I know the way!

* I think I need some practice especially on item \#21

* I have recently finished my literature review for my project and had some difficulty in identifying problems that could be improved and am still learning the basics of my field.

* Since I have a master's degree and have drafted papers, the answers are somewhat influenced by my experience.

Comments are the end of the course were:

* This class helped me to learn how to create a budget and justification and biosketch. I have thought through the methodology before but never written it down in such detail. Also the presentation was a big help in communication. 
* The questions are very broad. It is really difficult to judge based on writing one proposal in this class. I tried my best to answer them reasonably.

The change in average responses from the beginning to the end of the class is more apparent when the different from post-course to pre-course is examined. This is shown in Figure 3.

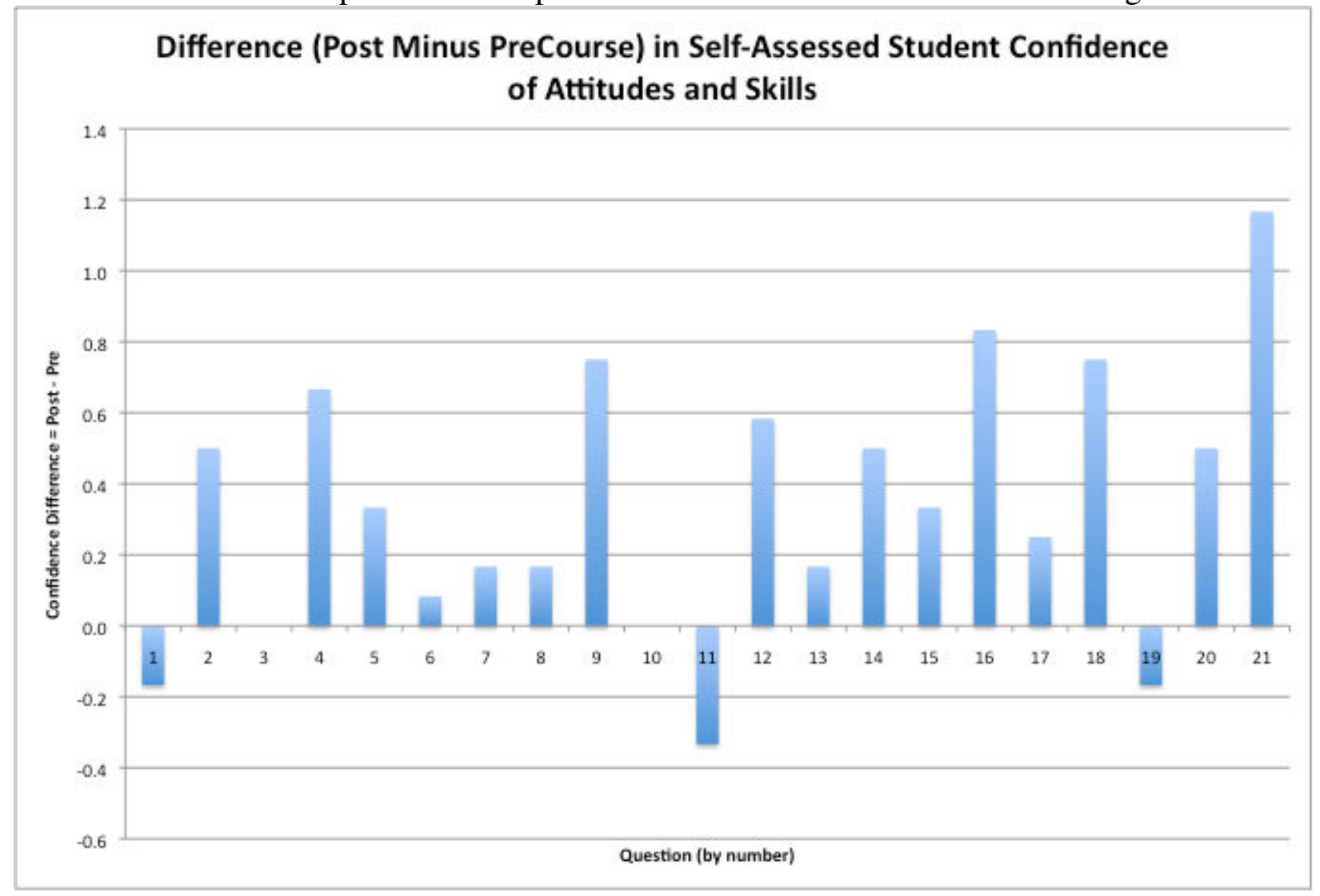

Figure 3: Difference between post and pre-course survey responses for students by question.

\section{Faculty Assessment Results}

Faculty from the department of chemical engineering as well from outside the department were asked to serve as committee members. Each committee member was asked to read the final proposal, provide comments, and attend the oral defense, providing comments and questions during that. A total of 14 unique faculty served on the committees for the six students enrolled in the course and 13 responded to the survey.

The faculty survey was broken into three sections. Section A asked the faculty to rate the quality of different sections of the proposals this year compared to prior years. Section B asked the faculty to rate the student's foundational knowledge and section $\mathrm{C}$ asked the faculty rate the student's proficiency utilizing the literature.

In section A, faculty rated the quality of the 13 sections of the proposal and aspects of the defense. The key for translating the responses into numerical values was $5=$ Much Better down to $1=$ Much Worse. These are listed below along with the average rating. In addition, the 
responses are compiled in Figure 4 by chemical engineering faculty, non-chemical engineering faculty, and overall.

Table 2: Average faculty ratings of the relative quality of proposal sections compared to prior years.

\begin{tabular}{|c|c|c|c|c|c|}
\hline & $\begin{array}{l}\text { Much } \\
\text { Better }\end{array}$ & Better & Same & Worse & $\begin{array}{l}\text { Much } \\
\text { Worse } \\
\end{array}$ \\
\hline 1. Project Summary & & 4.08 & & & \\
\hline 2. Introduction \& Motivation & & 4.08 & & & \\
\hline 3. Hypothesis \& Objectives & & 4.00 & & & \\
\hline 4. Literature Review & & 3.92 & & & \\
\hline 5. Methods Section & & 4.08 & & & \\
\hline 6. Mentoring \& Education & 4.67 & & & & \\
\hline 7. Budget \& Budget Justification & & 4.33 & & & \\
\hline 8. Biographical Sketch & & 4.00 & & & \\
\hline 9. Presentation Slides & & 4.08 & & & \\
\hline 10. Presentation Organization & 4.46 & & & & \\
\hline 11. Presentation Delivery & & 4.17 & & & \\
\hline 12. Answers to Questions & & 4.25 & & & \\
\hline 13. Originality of Research Idea & & & 3.46 & & \\
\hline
\end{tabular}

The most common feedback was that the course improved the quality of the proposals over that seen in prior years. However, while the quality was better, there remain substantial opportunities to improve the quality even further in subsequent offerings of this course. The quality of the Mentoring and Education sections was found to have the greatest improvement followed by presentation organization. It can be noted that presentation delivery and answers to questions were above the 'better' rating. The originality of the research idea was uniformly rated lower. This aspect of the proposals has been a highly debated one among the departmental faculty with differing views on the benefits to the students if the requirement is an original idea or simply their existing Ph.D. research project. This score is likely a reflection of that ongoing debate.

In section $\mathrm{B}$, faculty were asked to rate their assessment of the foundational knowledge that the student's demonstrated in chemical engineering (or their chosen field) either in their written proposal, oral defense, or while answering questions. Overall, faculty rated this as good with an average score of 3.4. The students rated themselves on this same question as 3.3. Next, faculty were asked to rate the student's foundational knowledge in their specific research field and rated that 3.8 while the students rated themselves as 3.2. There was relatively good agreement between students and faculty in these areas. 
The last section of the survey that faculty completed was $\mathrm{C}$ - Assimilate information from a comprehensive (yet succinct and thorough) literature review on a given research topic. Question 17 asked faculty whether the students had demonstrated adaptation of techniques described in articles in their own research. Faculty responses showed that they agreed (4.1) students had demonstrated this. Student responses to this same question were 3.8. Question 18 asked faculty whether students had demonstrated critiquing techniques and conclusions asserted in the literature. Average faculty responses were 3.6 while student responses were 4.1. Question 19 asked faculty what type of job students had done compiling a survey of the literature on a subject, organizing it logically, and presenting it to others in a manner that showed progression of knowledge and identified missing information. Average faculty responses were 4.0 while student responses were 4.2. Faculty rated the student's combination of skills from questions 17 through 19 as 4.2 while students rated these skills as 4.0.

Faculty were given the opportunity to comment on any aspect of the proposals and defenses. Comments were:

* Prior to enrolling in this course, my student's presentation skills were not nearly as developed as they are currently. During this short time, her critical thinking skills have improved. Her writing skills have improved as well. $\{$ Presentation $=$ phenomenal $\}$

* His international heritage positively influenced his global environmental perspective. His English skills are excellent, however he would benefit from an English proofreader. Better organization and time management than often seen in research proposals. Good balance of assertiveness and confidence versus humility.

Suggestions for improvements in subsequent years were also compiled. The most common comment was to have the students add a brief schedule or timeline. Another suggestion was to teach the students to develop an experimental matrix and include that in the proposal. 


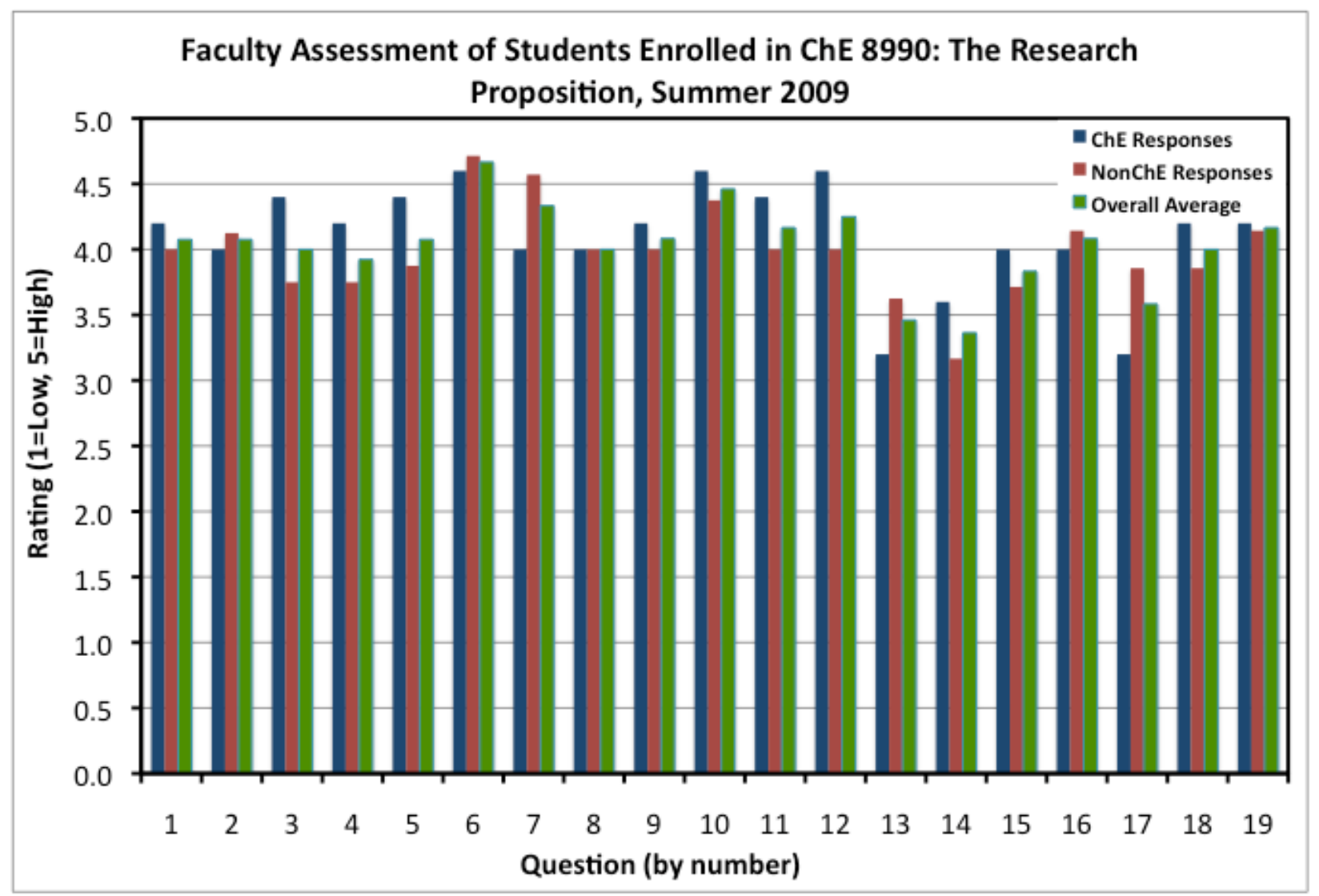

Figure 4: Average faculty responses by question. The first blue bar shows responses of chemical engineering faculty. The second red bar provides responses of non-chemical engineering faculty and the final green bar provides an overall average rating.

Evaluation sheets were provided to the 14 faculty members serving on the student committees that rated the student's written proposal and oral presentation. These were compiled for each committee to determine the spread across committee members and to concurrently determine if certain faculty were uniformly easy graders while other faculty were uniformly tough graders. One anticipated outcome of looking at the data in this fashion is to balance such easy / hard faculty on committees in subsequent years. An example evaluation sheet is provided in Appendix C.

Faculty ratings were compiled for all committees for which they served. Some faculty from departments other than chemical engineering served on only one committee. Table 3 compiles these ratings by faculty and tracks the number of committees each faculty member served. Three relative ratings are provided. The third column is the individual faculty member's rating minus the overall rating of the committee. The fourth column is this same difference for only the written component of the research proposal while the fifth column is that difference for the oral component. If the faculty member served on more than one committee, these differences are the average differences across all committees. Negative numbers indicate that faculty member rated lower than the committee average while positive numbers indicate higher individual faculty member's ratings than the committee average. The instructors for the course are faculty D and 
faculty I and both are just slightly lower than average ratings. The range of values in the table are -7 to +11 . Both extremes occur for faculty who served on only one committee and thus did not have the advantage of comparison with other students. The range for faculty who served on more than one committee is -5 to 5 . In future years, balance can be added to the committees to ensure that a hard grader (-5) is offset by a more lenient grader (+5). Examining the range of scores for chemical engineering faculty (starred in the table), the range is only -3 to 5 . This range of scores was not viewed as a concern and faculty bias was determined to not be a factor in the final grades for students.

Table 3: Comparison of individual faculty ratings of student performance from the overall committees rating. Starred faculty are from chemical engineering.

\begin{tabular}{|ccccc|}
\hline Faculty & \# Committees & Avg(FacTotal-Final) & Avg(Written - Final) & Avg(Oral-Final) \\
\hline A - Average & 4 & -5 & -3 & -1 \\
\hline B* - Average & 3 & -1 & 1 & -2 \\
\hline C* - Average & 3 & 4 & 1 & 3 \\
\hline D* - Average & 7 & -1 & -1 & -1 \\
\hline E* - Average & 3 & 5 & 2 & 3 \\
\hline F & 1 & 1 & -1 & 2 \\
G & 1 & 6 & 1 & 5 \\
\hline H-Average & 3 & -2 & 0 & -2 \\
\hline I* - Average & 6 & -3 & 0 & -3 \\
\hline J & 1 & 5 & 1 & 4 \\
\hline K & 1 & -7 & -5 & -3 \\
\hline L & 1 & 1 & -1 & 2 \\
\hline M & 1 & 11 & 5 & 6 \\
\hline N & 1 & & 3 & \\
\hline
\end{tabular}

\section{Changes for the 2010 Course Implementation}

The overall structure and goals of the course were found to be beneficial and are not expected to change for the 2010 implementation. Emphases and timing will be however be improved upon. The items to place greater emphasis in 2010 were identified as:

* Iterate with the students on a hypothesis earlier in the 10 week class. Lecture 9a was to finalize research topic for your proposition and a 1-page proposition with clear proposal objectives was turned in. However, many students were unable to focus their hypothesis effectively after this one round of feedback and this impacted the 
quality of their first draft. One idea is to expand to a 2-page proposition with clear proposal objectives due one week after 9 a.

* Provide structured guidance to the students on design of experiments. This was treated as a secondary topic in 2009 and it became apparent that if it was promoted to a primary topic covered in about week 5 in 2010, the students would greatly benefit.

* Concurrent with the experimental plan, a schedule of activities or timeline will also be required in 2010. This may be combined with the design of experiments assignment or may be a separate item to be turned in that includes both research and education / outreach components.

* In 2010, student writing will be routed through the university's writing center 3 to 4 days before being turned into the instructors of the course. This will be a mandatory requirement so that the students can more effectively learn technical writing skills or if they are English as a Second Language students, can improve their English writing skills as well.

* Student perceived proficiency in reading, critiquing and assimilating information from archival technical journal articles will also be examined in greater detail. Students formally reviewed 1 article during the 2009 course. In 2010, it may be beneficial to have the students read, critique and compare two articles side by side in order to have a better grasp of good / bad data communication, analysis, and delivery in technical writing.

* Student perceived proficiency in knowledge in their research field did not increase to the degree that the instructor's expected (question 8). This trend will be studied in future implementations of the course. Upon having the students select their proposal topic, it may be a good exercise for them to conduct a brainstorming session on what they know about that topic, then revisit that brainstorm at the end of the class.

Additionally, the instructors learned how to more effectively provide guidance and subsequent feedback to the students in the course. Lectures and supplemental material will be expanded and / or streamlined to more effectively and efficiently communicate important concepts to the students. Reading and critiquing the proposal components and the full proposals was a timeconsuming task. Two or more instructors are highly recommended for this course.

\section{Interpretations and Conclusions}

This course was seen as a substantial step forward in the department in strategically training graduate students with the research skills that would make them successful in their graduate careers. The first implementation of the course was overall deemed effective at training students to prepare research proposals. The anecdotal evidence from faculty members involved in the proposal evaluation process indicated that the quality of the proposals and presentations was superior compared to the case of no guidance. This is supported by the compiled survey results. However, room exists in subsequent years for improvement and such areas have been identified.

The student's confidence and level of comfort in the preparation of proposals and presentations was enhanced by the course. This was apparent to the student's research advisors over the fall semester and was also supported by the assessment results. In subsequent years, a student-tostudent mentoring scheme may also be employed to help guide the students through the course. 


\section{Bibliography}

1. Ollis, D.F. “The Research Proposition,” Chemical Engineering Education, 29 (4), pgs 222-229, 1995.

2. Penrose, AM and SB Katz, Writing in the sciences: Exploring conventions of scientific discourse, 3rd Ed. Longman, New York: 2010. ISBN-13: 978-0-205-61671-8

3. Van Wagenen, K. Writing a Thesis: Substance and Style. Prentice Hall, New Jersey: 1991. ISBN: 0-13971086-8

4. Wilson EB, An Introduction to Scientific Research, Dover Publications, New York, 1990. ISBN: 0-486-665453

5. Lanham, RA, Revising Business Prose, 4th Ed. Longman, New York, 2000. ISBN: 0-205-30944-5

6. Harrison, R.G, M.U. Nollert, D.W. Schmidtke, and V.I. Sikavitsas, "The Research Proposal in Biochemical and Biological Engineering Courses," Chemical Engineering Education, 40(4), 323-326, 2006.

7. Holles, J.H. "A Graduate Course in Theory and Methods of Research," Chemical Engineering Education, 41(4), 226-232, 2007.

8. Burrows, V.A. and S.P. Beaudoin, "A Graduate Course in Research Methods.” Chemical Engineering Education, 35(4), 236, 2001.

9. Fagerberg, I. and A. Norberg, "Learning by doing - or how to reach an understanding of the research method phenomenological hermeneutics," Nurse Education Today, 29: 735-739, 2009.

10. Tang, Bor Luen and Yunn Hwen Gan, "Preparing the Senior or Graduating Student for Graduate Research" Biochemistry and Molecular Biology Education, 33(4): 277-280, 2005.

11. Prevatt, P.O. "On the Job versus Graduate School Training of Forensic Engineers - An Instructor and Professional Engineer's View." J of Performance of Construction Facilities, 24(1):78-86, 2010.

12. Barnes, T.A., I.R. Pashby, and A.M. Gibbons. "Working Toward the Successful Deployment of Post -graduate Research Students on University-Industry Collaborative R\&D Projects," American Society for Engineering Education Proceedings, 2002.

13. Trotz, M.A., A. Stuart, D. Yeh, H.E. Muga, L.Phillips, J.R.Mihelcic, "Non-traditional University Research Partners that Facilitate Service Learning and Research for Sustainable Development from the Undergraduate to Graduate Level," American Society for Engineering Education Proceedings, 2009.

14. Lilja, D.J. "Suggestions for Teaching the Engineering Research Process," American Society for Engineering Education Proceedings, 1997.

15. Frank, R.C. "A Brief Introduction to Scientific Research,” Augustana Research Foundation, Rock Island, IL: 2006. ISBN-13: 978-0-9788495-0-4.

16. Moore, F.L. and M.L. Penn, "Finding your North: Self-Help Strategies for Science-Related Careers," PotentSci LLC, Emeryville, CA: 2005. ISBN: 0-9766205-0-2.

17. Lazarus, B.B., L.M. Ritter, and S.A. Ambrose, "The Woman's Guide to Navigating the Ph.D. in Engineering and Science," IEEE Press, New York: 2001. ISBN: 0-7803-6037-0.

18. Michaelson, H.B. "How to Write and Publish Engineering Papers and Reports, $3^{\text {rd }}$ Edition," Oryx Press, Phoenix,AZ: 1990. ISBN: 0-89774-650-3.

19. Reichert, W. M., T. Daniels-Race, and E.H. Dowell, "Time-Tested Survival Skills for a Publish or Perish Environment." Journal of Engineering Education, 91(1), 133-137, 2002.

20. Smart, J.C., "Perspectives of the Editor: Attributes of Exemplary Research Manuscripts Employing Quantitative Analysis." Research in Higher Education, 46(4), 461-477, 2005.

21. Turnitin Originality Checking \& Plagiarism Prevention Online Software www.turnitin.com, accessed 7 January 2010. 


\section{Appendix: Copies of Assessment Tools}

\section{A. Post-course Assessment Completed by Students.}

NOTE: The pre-course assessment tool was very similar to this one so is not duplicated in this document. The purpose was to just student attitudes and self-measured skills from the beginning of the course to the end.

What is your birthday (dd mm yyyy)? [Used to match pre and post surveys]

What is your current phone number? [Used to match pre and post surveys]

Part A: Attitudes and Time:

1. Now that you have completed the course, what are your feelings toward the class?

a. Very scared

b. Scared

c. Neutral

d. Easy

e. This was a piece of cake!

2. What is your exiting attitude toward this class?
a. This course taught me essential skills that will or has already made me better / more productive as a graduate student
b. This course provided some skills that I will use
c. Neutral
d. I didn't learn important skills
e. I didn't learn anything that will benefit me.

3. I actually spent the following hours per week on this class
a. Less than 10
b. $11-20$
c. 21-30
d. more than 30

Please re-assess your proficiency in the following areas.

Part B: Reading, critiquing and assimilating information from archival technical journal articles.

4. I have experience conducting literature searches.
a. Strongly agree
b. Agree
c. Neutral
d. Disagree
e. Strongly disagree

5. I am confident that I can obtain a complete profile of published work (past and present) on a specific research topic.
a. Strongly agree
b. Agree
c. Neutral
d. Disagree
e. Strongly disagree 
6. Please rate your experience at reading archival journal articles in your research area.

a. Very proficient (can read / skim it once and understand all)

b. Proficient (can read closely once and understand all)

c. Sufficient (can understand most after rereading closely)

d. Inefficient (can understand some after rereading closely)

e. Very inefficient (understand little after much rereading)

Part C: Knowledge and Designing of Experimental Plan.

7. I would rate my foundational knowledge in my discipline as:

a. Excellent (at the same level as my professors)

b. Very Good (I could carry on a lengthy discussion with my professors)

c. Good (I'm sufficient)

d. Fair (I struggle, but can figure most things out)

e. Poor (I doubt I should have been accepted to grad school)

8. I would rate my foundational knowledge in my research field.

a. Excellent (at the same level as my professors)

b. Very Good (I could carry on a lengthy discussion with my professors)

c. Good (I'm sufficient)

d. Fair (I struggle, but can figure most things out)

e. Poor (I doubt I should have been accepted to grad school)

9. Given a good understanding of the research question, I would rate my abilities to design a comprehensive experimental plan as follows:

a. Excellent (this would only take a few hours and would rival what my professor does)

b. Very Good

c. Good (I'm sufficient and can figure a good matrix out)

d. Fair (I struggle and need guidance)

e. Poor (I can't do this on my own)

10. Please comment on anything that influenced your answers to 1 through 9 (Parts A through C):

The skills we taught in this course are included in questions 11 through 21 . Please rate your current level of knowledge for

Part D: Assimilate information from a comprehensive (yet succinct and thorough) literature review on a given research topic

11. I have experience adapting techniques described in articles in my own research.

a. Strongly agree (I do this regularly without guidance from anyone)

b. Agree (I recognize opportunities for this and need to discuss with others)

c. Neutral (I recognize relations when others point them out to me)

d. Disagree (I rarely see how literature is related to my project)

e. Strongly disagree (articles are from a different planet than my project)

12. I have experience critiquing techniques and conclusions asserted in the literature.

a. Strongly agree (regularly recognize trends and limitations, others rarely recognize things I didn't already see)

b. Agree (regularly recognize trends \& limitations, learn from other's insights)

c. Neutral (sometimes recognize limitations, learn from other's insights)

d. Disagree (Rarely recognize trends \& limitations, rarely follow other's insights)

e. Strongly disagree (I feel lost) 
13. I have experience compiling a survey of the literature on a subject, organizing it logically, and presenting it to others in a manner that shows progression of knowledge and suggests what information is missing.

a. Strongly agree (I can do this independent of guidance)

b. Agree (Can do some independent, need some guidance)

c. Neutral (Need guidance, can follow instructions)

d. Disagree (Need guidance, sometimes need repeat to follow instructions)

e. Strongly disagree (please don't make me do this!)

14. I have experience analyzing raw data (list of numbers) to determine trends and dependencies.

a. Strongly agree (I can do this independent of guidance)

b. Agree (Can do some independent, need some guidance)

c. Neutral (Need guidance, can follow instructions)

d. Disagree (Need guidance, sometimes repeat guidance to follow instructions)

e. Strongly disagree (please don't make me do this!)

15. I have experience writing research articles that combine the skills from 11 through 14.

a. Strongly agree (I can do this independent of guidance)

b. Agree (Can structure a complete first draft, need guidance refining to final draft)

c. Neutral (Need guidance structuring first draft, guidance refining to final draft)

d. Disagree (Need guidance on some sections and guidance on first through final drafts)

e. Strongly disagree (Need guidance on each section and step by step approach)

Part E: Other skill sets

16. I would rate my ability to identify and articulate knowledge missing from my research field as:

a. Excellent (at the same level as my professors)

b. Very Good (I could do as good as my professors, but it would take me longer)

c. Good (I'm sufficient with some guidance)

d. Fair (I struggle, but can sometimes identify missing knowledge / next research)

e. Poor (I think everything worth researching has already been done)

17. I would rate my ability to develop a well-defined hypothesis that probes an important and relevant research problem as:

a. Excellent (at the same level as my professors)

b. Very Good (I could do as good as my professors, but it would take me longer)

c. Good (I'm sufficient with some guidance)

d. Fair (I struggle, but could write possible hypothesis with major revisions)

e. Poor (I couldn't do this at all)

18. I would rate my ability to describe a detailed method of approach (experimental or otherwise) to obtain missing knowledge as:

a. Excellent (at the same level as my professors)

b. Very Good (I could do as good as my professors, but it would take me longer)

c. Good (I'm sufficient with some guidance)

d. Fair (I struggle, but could write possible methods with major revisions)

e. Poor (I couldn't do this at all)

19. I would rate my ability to write in detail about data analysis / interpretation and impact of expected results as:

a. Excellent (at the same level as my professors)

b. Very Good (I could do as good as my professors, but it would take me longer) 
c. Good (I'm sufficient with some guidance)

d. Fair (I struggle and need substantial guidance on this)

e. Poor (I couldn't do this at all)

20. I would rate my ability to contextualize the importance of this within the larger research field as:

a. Excellent (at the same level as my professors)

b. Very Good (I could do as good as my professors, but it would take me longer)

c. Good (I'm sufficient with some guidance)

d. Fair (I struggle and would need substantial guidance)

e. Poor (I couldn't do this at all)

21. I am experienced crafting a Budget, Biosketch (i.e credentials document), and Facilities and Resources.
a. Strongly Agree
b. Agree
c. Nuetral
d. Disagree
e. Strongly Disagree

22. Please comment on anything that influenced your answers to 11 through 21 (skills taught in this class): 


\section{B. Post-course Assessment Completed by Faculty.}

How many proposal defenses (i.e. qualification exams) have you participated in prior years?

How many proposal defenses are you participating in this year?

A. Please rate the quality of the following sections of the proposals this year compared to prior years:

\begin{tabular}{|l|l|l|l|l|l|}
\hline & $\begin{array}{c}\text { Much } \\
\text { Better }\end{array}$ & Better & Same & Worse & $\begin{array}{c}\text { Much } \\
\text { Worse }\end{array}$ \\
\hline 14. Project Summary & & & & & \\
\hline 15. Introduction \& Motivation & & & & & \\
\hline 16. Hypothesis \& Objectives & & & & & \\
\hline 17. Literature Review & & & & & \\
\hline 18. Methods Section & & & & & \\
\hline 19. Mentoring \& Education & & & & & \\
\hline 20. Budget \& Budget \\
Justification
\end{tabular}

B. Based on your observations today, how would you rate the students?

\section{The student's foundational knowledge in chemical engineering is:}
a. Excellent (at the same level as professors)
b. Very Good (could carry on a lengthy discussion with professors)
c. Good (sufficient)
d. Fair (Student's struggle, but can figure most things out)
e. Poor (Student's should not have been accepted to grad school)

\section{The student's foundational knowledge in their specific research field is:}

a. Excellent (at the same level as professors) 
b. Very Good (could carry on a lengthy discussion with professors)

c. Good (sufficient)

d. Fair (Student's struggle, but can figure most things out)

e. Poor (Student's should not have been accepted to grad school)

Part C: Assimilate information from a comprehensive (yet succinct and thorough) literature review on a given research topic

17. Students demonstrated adaptation of techniques described in articles in their own research.
a. Strongly agree
b. Agree
c. Neutral
d. Disagree
e. Strongly disagree

18. Students demonstrated critiquing techniques and conclusions asserted in the literature.
a. Strongly agree
b. Agree
c. Neutral
d. Disagree
e. Strongly disagree

19. Students demonstrated compiling a survey of the literature on a subject, organizing it logically, and presenting it to others in a manner that shows progression of knowledge and suggests what information is missing.
a. Strongly agree
b. Agree
c. Neutral
d. Disagree
e. Strongly disagree

20. Students demonstrated writing that combine the skills from 17 through 19.
a. Strongly agree
b. Agree
c. Neutral
d. Disagree
e. Strongly disagree

21. Please comment on anything that influenced your answers to 14 through 20: 
22. Using the back if necessary, please provide suggestions for improvements for next year (content, logistics, and other). 


\section{Committee Evaluation Tool}

STUDENT:

EVALUATOR:

Written proposal:

$1 . \quad$ Knowledge of "state of the

engineering/science" in the field. Assess the perspective, critical analysis of existing body of literature (10 points).

2.

selected research problem: Clarity of hypothesis, originality, and feasibility of success (10 points).

Suitability of

3.

Effectiveness

of proposed research plan: understanding of relevant physical and chemical phenomena, chance of success, is methodology current and viable? Proposed experiments will prove / disprove hypothesis (10 points).

4.

effectiveness of writing: conciseness, logic, clarity (10 points).

Quality and

5.

Degree of innovation in proposed research (10 points).

Creativity:

Written Subtotal:

\section{Oral Presentation:}

6. Quality and effectiveness of presentation: Conciseness, logic, clarity, impact, thoroughness (10 points).

7. Knowledge of field of research topic. Demonstrates both depth and breadth of knowledge (10 points).

8. Contextualization of proposed effort within the larger scope of discipline. Realistic portrayal of the intellectual merits and limitations of proposed approach (10 points).

9. Mastery of chemical engineering principles (10 points).

10. Creativity in responding to questions (ability to think on feet) with references to literature providing a foundation for the proposed work (10 points).

Oral Subtotal:

FINAL SCORE: 